\title{
The Best Way to Teach Phrasal Verbs: Translation, Sentential Contextualization or Metaphorical Conceptualization?
}

\author{
Mansoor Ganji \\ English Department, Chabahar Maritime University, Iran \\ Email: ganji@cmu.ac.ir
}

\begin{abstract}
This study investigates the metaphor's central position in the memorization, retention and prediction of the meaning of phrasal verbs. To this end, 45 Iranian EFL learners from Chabahar Maritime University were divided into three groups. In control group, the phrasal verbs were presented with their Farsi (students' mother tongue) equivalents and students were asked to memorize them on their own as it is the traditional method of teaching phrasal verbs. Experimental group I received the phrasal verbs in the context of a sentence, and students were asked to make new sentences with them in the class. And the experimental group II received the orientational metaphors underlying the meaning of the particles of phrasal verbs. All the three groups took three tests in which the correct particles of the phrasal verbs had to be provided. The first test, carried out just two hours after the instructions, dealt with the taught phrasal verbs. The same test was conducted five weeks later to measure the long term retention of phrasal verbs' meaning. But the third test dealt with 20 untaught phrasal verbs which had the same particles as the taught ones. One-way ANOVA results revealed that the difference between the groups' performances on the immediate test was not statistically significant, while the efficiency of metaphorical conceptualization, and sentential contextualization on the delayed test, and untaught test was considerable. There was a slight difference between the two experimental groups, but it was not statistically significant. The study ends with some suggestions for the teaching of phrasal verbs and the possible factors contributing to their difficulty.
\end{abstract}

Index Terms-translation, retention, phrasal verbs, sentential contextualization, metaphorical conceptualization

\section{INTRODUCTION}

Idioms are odd ducks. They seem to act very much like normal language, but they are quite different in many ways. It's been said that "If natural language had been designed by a logician, idioms would not exist". But exist they do, and not only that, they represent a rich vein in language behavior, and so they cry out for explanation. (P. N. Johnson- Laird in a foreword to a collection of works on idioms, cited in Tim Ifill, 2002). The category of idioms is a mixed bag. It involves metaphors, metonymies, and pairs of words, idioms with it, similes, sayings, phrasal verbs, grammatical idioms, and others. But where do idioms come from, and what kind of structure do they have, if any? (Kovecses \& Szabo, 1996, 128).

In the "Traditional View", idioms are regarded as a special set of the larger category of words. They are assumed to be a matter of language alone; that is, they are taken to be items of the lexicon that are independent of any conceptual system. According to the this view, all there is to idioms is that they have certain syntactic properties and have a meaning that is special, and relative to the meanings of the forms that comprise it.

Developments in cognitive linguistics have led to improvements in descriptions of figurative language and facilitated our understanding of the interrelationships of many idiomatic expressions. Cognitive linguists are primarily interested in the underlying cognitive motivations for language comprehension (Black, 2002). Although there is no complete predictability, it can be suggested that there is a great deal of systematic conceptual motivation for the meaning of most idioms. Many or perhaps most idioms are products of our conceptual system. An idiom is not just an expression that has meaning that is somehow special in relation to the meanings of its constituent parts, but it arises from our more general knowledge of the world (Bilkova, 2000). The cognitive linguistic notion of conceptual metaphor is highly valuable in undertaking studies of idiomatic expressions, and therefore can facilitate their teaching (Black, 2002).

Conceptual metaphor is clearly a powerful tool for helping us understand a great deal of idiomatic language, so it is reasonable to believe that it will also help us to unravel the mysteries of phrasal verbs, one category of idioms, and their particles (Rundell, 2005a).

Although it is impossible to generalize with confidence about language in general from a restricted study such as this one, the fact that cognitive devices are at work in the comprehension and interpretation of idioms would suggest that metaphorical thinking may also function in facilitating the learning of idiomatic phrasal verbs. It is hoped that this study will make a modest contribution to this goal. 


\section{A. Statement of the Problem}

Idioms are omnipresent in the world's languages. Despite their pervasiveness, idioms are often a stumbling block to second and foreign language learners and helping learners to progress from the literal to the metaphoric meaning is a challenge for language teachers. Although some idiomatic phrases are usually included in first-level course-books, they are usually presented as exceptions to the rule. In later phases, students are often referred to specialized learner dictionaries of idioms, phrasal verbs, etc.

Phrasal verbs create special problems for students because there are so many of them and the combination of verb and particle seem so often completely random. These difficulties are sometimes increased by the way in which phrasal verbs are presented in course books or by teachers telling students that they will just have to learn them by heart, thereby implying that there is no system. However, if one looks closely at the particle, patterns start to emerge which suggest that the combinations are not so random at all (Side, 1990).

\section{B. Purpose of the Study}

In this study, the distinctive role of conceptual metaphor in explaining the underlying link between the parts of phrasal verbs and the meaning of these idioms will be given a sound analysis. In particular, this study aims to make a comparison between the three methods of Translation, Sentential Contextualization (seeing and using them in sentences) and Metaphorical Conceptualization, and to measure the degree of effectiveness with which the meaning of idiomatic phrasal verbs can be memorized, retained, and predicted through these methods of teaching. The implementation of the present study aims at addressing the following research questions.

1) Is there any significant difference between Experimental and Control Groups due to the effects of Translation, Sentential Contextualization and Metaphorical Conceptualization on the immediate test of taught phrasal verbs?

2) Is there any significant difference between Experimental and Control Groups due to the effects of Translation, Sentential Contextualization and Metaphorical Conceptualization on the delayed test of taught phrasal verbs?

3) Is there any significant difference between Experimental and Control Groups due to the effects of Translation, Sentential Contextualization and Metaphorical Conceptualization on the delayed test of untaught phrasal verbs?

As a result, the following three null hypotheses were formulated.

1). There is no significant difference between Experimental and Control Groups due to the effects of Translation, Sentential Contextualization and Metaphorical Conceptualization on the immediate test of taught phrasal verbs.

2). There is no significant difference between Experimental and Control Groups due to the effects of Translation, Sentential Contextualization and Metaphorical Conceptualization on the delayed test of taught phrasal verbs.

3). There is no significant difference between Experimental and Control Groups due to the effects of Translation, Sentential Contextualization and Metaphorical Conceptualization on the delayed test of untaught phrasal verbs.

\section{PREvious Studies}

It has been shown that the constituent parts of many idioms systematically contribute to their overall figurative meanings (Gibbs, 1997). This view demonstrates that the way people conceptualize the world around them is actually projected into the idiomatic language they use to express their ideas or feelings. Gibbs and O'Brien (1990, cited in Bilkova, 2000) have shown in a number of experiments that individual words systematically contribute to the overall figurative interpretations of idioms. Lakoff in his famous publication Women, Fire, and Dangerous Things: What Categories Reveal About the Mind? (1987) argues that metaphor permeates language to the extent that much of our thinking is metaphorical.

Skoufaki (2003) examined whether second language learners used conceptual metaphors to guess at the meaning of idiomatic phrasal verbs. Greek adult intermediate learners of English wrote their guesses of the meaning of unknown idiomatic phrasal verbs in the context of a sentence and described the type of conceptual metaphor that led them to verb interpretation. Results indicated the unlimited use of conceptual metaphors as a strategy for guessing of an idiomatic meaning.

Another research in this regard was carried out by Rundell (2005b) as regards the metaphorical meaning of a couple of particles (over and back). Referring to the basic, literal meaning of the particle over, he stated that we can see several further ideas that develop as metaphorical alterations on these spatial concepts, including: - being in a higher position (preside over) - powerfully affecting someone's emotions (swept over) - and trying to hide a truth (skates over). Rundell (2005b) by referring to one of the senses of back that is the idea of returning to a place you were in before, concluded that the more abstract notions of time is often conceptualized in terms of space.

Crutchley, A. (2007) analyzed the responses of a large stratified sample of 6- to 11-year-old children to a forcedchoice picture selection task testing verb+particle constructions such as 'look up' and 'call off'. Distracter analysis revealed that children may not apply simple decompositional semantic strategies to comprehend unfamiliar verbs. They made use of the syntactic features of the verbs, and contextual information only in certain circumstances. Children's choices of distractors showed that they employed a holistic rather than an analytic approach to comprehension of unfamiliar particle verbs.

Yasuda, Sachiko (2010) examined whether enhancing awareness of orientational metaphors of particles helps the acquisition of phrasal verbs by Japanese English as a foreign language (EFL) students. The students in the control group 
learned a number of phrasal verbs using traditional instruction, while those in the experimental group received the same input through a cognitive linguistic approach. The students in both groups were then asked to fill in the missing adverbial particles of the phrasal verbs. Results showed that the students in the experimental group performed significantly better than those in the control group, implying that when the target idioms are not stored as a unit in learners' mental lexicon, learners who are aware of conceptual metaphors may rely on metaphorical thought to produce an appropriate adverbial particle.

Nassaji, H. and Tian, J. (2010) studied and compared the effectiveness of two types of output tasks (reconstruction cloze tasks and reconstruction editing tasks) for learning English phrasal verbs. He wanted to see if doing the tasks collaboratively led to greater gains of knowledge of the target verbs than doing the tasks individually and also whether the type of task made a difference. The results revealed that completing the tasks collaboratively led to a greater accuracy of task completion than completing them individually. However, collaborative tasks did not lead to significantly greater gains of vocabulary knowledge than individual tasks. The findings, however, showed an effect of task type, with the editing tasks being more effective than the cloze tasks in promoting negotiation and learning.

Khatib, M. and Ghannadi, M. (2011) investigated the effectiveness of interventionist and non-interventionist approaches to the recognition and production of phrasal verbs. The results of the study revealed the superiority of interventionist groups over the non-interventionist group in both recognition and production of phrasal verbs. In addition, the interventional explicit group greatly outperformed the interventional implicit group in both recognition and production.

\section{RESEARCH METHODOLOGY}

\section{A. Setting and Participants}

Participants of this study were 45 Iranian EFL learners attending Chabahar Maritime University. They were marine engineering students who were doing their third year of at this university. They were all males, since this university does not accept girls in this field, and their age ranged from 20 to 24 years old. They were chosen from 57 students who were in three different classes. Twelve of the students were excluded from the study because they did not participate in all the tests. It is worth mentioning that the syllabus in this university is totally different from those of other universities, and students are required to attend special courses in grammar, reading and conversation. Besides, most of them have gone to English classes in Private institutes before being admitted to the university for at least two years. They attend English classes at least three sessions a week, each one lasting for 90 minutes.

\section{B. Research Design}

The research design of the present study is quasi-experimental, since intact classes are used, not randomly chosen students. It obtains 45 university students from three General English classes. The students are not randomly selected from a large number of students to represent the university students of Iran. They will receive three types of treatment, one traditional method and two modern methods. The first group is being taught by the traditional method of teaching phrasal verbs along with their translation, the second group is taught by sentence making, and the last one is taught through becoming familiar with the conceptual metaphors of the particles of the phrasal verbs.

\section{Instrumentation}

Four types of instruments including immediate test of taught phrasal verbs, delayed test of taught phrasal verbs, test of untaught phrasal verbs, and one-way ANOVA were utilized in this study to address the research questions. Two objective teacher-made fill- in-the-blank tests of phrasal verbs were used in this study. There was no pre-test in this study. The first test was administered just two hours after the completion of the treatment sessions. The first test consisted of 20 fill-in-the-blank items in which the particles of the taught phrasal verbs were missing, and the students were expected to complete the sentences with appropriate particles. This test was conducted to measure the ability of the students to remember the meaning of taught phrasal verbs after a short time. The same test was conducted five weeks later, because it was designed to measure the ability of the students to remember the taught phrasal verbs after a long time. The last test had 20 untaught phrasal verbs, but with the same particles, to assess the students' ability in guessing the meaning of untaught phrasal verbs. Finally, after recording the students' scores, a one-way ANOVA was used to measure the differences in the performances of the students of the three groups in the immediate test of taught phrasal verbs, delayed test of taught phrasal verbs, and the test of untaught phrasal verbs.

\section{Data Collection Procedure}

The study dealt with some idiomatic phrasal verbs in English. The number of phrasal verbs that have idiomatic meaning is very large in English. Although several hundred phrasal verbs exist in English, only those that have the adverbial particles up, down, off and out were included in this study. First of all, the participants were selected from among 57 students. The participants were randomly divided into three groups: one Control Group, and two Experimental Groups, each one with 15 students.

All the students took three tests. The first test, conducted just two hours after the treatment, involved filling in the missing adverbial particles of the 20 taught phrasal verbs in the context of a sentence (see appendix A). The second test, 
which is the same as the first test, was conducted five weeks later to measure the students' ability in retaining the meaning of phrasal verbs after 5 weeks. And the last test included 20 questions, including 20 new phrasal verbs which were not taught in any of the classes, but had the same particles with the same meaning as the taught ones. These 20 phrasal verbs were placed in the context of a sentence (See appendix B). The adverbial particles up, down, off and out were left out of the resulting sentences. All the sentences were taken from Longman Dictionary of Contemporary English Idioms; Longman Dictionary of Phrasal Verbs and Oxford Advanced Learner's Dictionary.

In the case of Control Group, the procedure was as follows: The researcher conducted two training sessions for the students, each one lasting around 45 minutes. The 20 phrasal verbs were written on the board along with their Farsi equivalents (10 phrasal verbs per session). The meanings of these 20 phrasal verbs were explained to the students. Students were asked to memorize the meaning of each phrasal verb.

In Experimental Group I, the researcher had two training sessions. In each session, ten phrasal verbs were taught to the students. The phrasal verbs were written on the board, their meanings were explained to the students in the context of a sentence, and at the end, the students themselves made sentences with the phrasal verbs, and read their sentences aloud in the class to check if they have got the meaning correctly.

In Experimental Group II, the 20 phrasal verbs were grouped according to the conceptual metaphors they manifest (see appendix C). Again, the researcher conducted two training sessions for this Experimental Group each with a 45minute block of time. As a result, 20 orientational metaphors (five for each particle) were identified. The twenty orientational metaphors with examples were put on the board and explained to the Experimental Group students, 10 orientational metaphors per session.

Two hours after the completion of the explanation by the teacher/researcher and memorization of the phrasal verbs by students, all the three groups were asked to fill in the missing adverbial particles in all twenty sentences. This test was called immediate test of taught phrasal verbs, because it was just two hours after the instruction, and it tested the verbs that were taught in the classes. All the groups were tested separately in their regularly-scheduled language classes. Students were given 20 minutes to complete the 20 sentences. Five weeks later, students were provided with the same 20-item fill-in-the blank test in which they were again required to supply the particles up, off, down and out. This test was exactly the same as the first test, but administered 5 weeks later to measure their ability to remember the meaning of the verbs after a longer time. The third test consisted of 20 untaught phrasal verbs, but with the same particles as the taught ones. The rationale for the administration of the third test was to see whether students can cope with a more creative task in the long term in which the adverbial particles of previously untaught phrasal verbs have to be provided. The researcher then measured the effectiveness with which the completion task was performed in terms of the number of correct responses to the questions in both Experimental and Control Groups. The answers to the tests were either right or wrong, and scored accordingly. A subject's score was the number of correct responses.

\section{E. Data Analysis}

The scores of the students on the Immediate Test of Taught Phrasal Verbs, Delayed Test of Taught Phrasal Verbs, and Test of Untaught Phrasal Verbs were recorded. Each test had 20 questions, so the scores ranged from 0 to 20 . The results were analyzed using SPSS version 17. Descriptive statistics and one-way ANOVA were exploited to see if there were differences between the three groups' performances on the tests.

\section{RESULTS}

After the administration of the Tests of phrasal verbs, the results obtained from these three groups on the production of phrasal verbs were compared by using a one-way ANOVA. Then in order to ensure where differences reported by ANOVA exactly occurred, a Scheffé test was used. The results of the study are divided into three sections, each section relating to one research question.

\section{A. Immediate Test of Taught Phrasal Verbs}

This section deals with the results of the first test, and it is related to the first research question. After the administration of the Immediate Test of Taught Phrasal Verbs, the scores of the students in the three groups of Translation Group (Control Group), Sentential Contextualization Group (Experimental Group I), and Metaphorical Conceptualization Group (Experimental Group II) were recorded. Table 1 displays the descriptive statistics on the Immediate Test of Taught Phrasal Verbs that were administered to students just two hours after the instruction. As the table indicates, there is a slight difference among the means of these three groups of participants. The Control Group which was taught through the traditional method of providing mother tongue translation and were asked to memorize the phrasal verbs themselves got the highest mean in this test, 15.80. The lowest mean belongs to the Experimental Group II that is quite new to the students. 
TABLE 1:

DESCRIPTIVE STATISTICS OF IMMEDIATE TEST OF TAUGHT PHRASAL VERBS

\begin{tabular}{|l|l|l|l|l|l|l|}
\hline Group & $\mathrm{N}$ & Mean & Std. Deviation & Minimum & Maximum & Std. Error Mean \\
\hline Control & 15 & 15.80 & 3.00 & 8 & 19 & 0.77 \\
\hline Experimental I & 15 & 15.33 & 2.28 & 11 & 18 & 0.59 \\
\hline Experimental II & 15 & 15.20 & 2.42 & 11 & 19 & 0.62 \\
\hline Total & 45 & 15.44 & 2.54 & 8 & 19 & \\
\hline
\end{tabular}

A one-way ANOVA was run to compare the mean scores of the three groups on the Immediate Test of phrasal verbs. The F-observed value is .222 (Table 2). This amount of F-value at 2 and 42 degrees of freedom is lower than the critical value of F, i.e. 3.22. Based on these results, it can be concluded that there was no significant difference between the mean scores of the three groups on the Immediate Test of Taught Phrasal Verbs. That is to say, the three groups were homogeneous in their performances on the Immediate Test of phrasal verbs, and the three different methods of teaching phrasal verbs in these three classes did not have any influence on the performances of the students in this test, even though, the control group did slightly better than the other two experimental groups. However, all the groups had high means; the reason might be that students can remember the meaning of phrasal verbs just because they have learned them hours ago.

TABLE 2:

ONE-WAY ANOVA FOR THE IMMEDIATE TEST OF TAUGHT PHRASAL VERBS

\begin{tabular}{|l|l|l|l|l|l|}
\hline & Sum of Squares & df & Mean Square & F & Sig. \\
\hline Between Groups & 2.978 & 2 & 1.489 & 0.222 & 0.802 \\
\hline Within Groups & 282.133 & 42 & 6.717 & & \\
\hline Total & 285.111 & 44 & & & \\
\hline
\end{tabular}

\section{B. Delayed Test of Phrasal Verbs}

In order to answer the second research question, the same test was administered 5 weeks after the instruction. It was called the Delayed Test of Taught phrasal verbs, because it had the same questions, but it was designed to measure the ability of the students to remember the meaning of taught phrasal verbs after 5 weeks. Table 3 shows the descriptive statistics of the Delayed Test of Taught phrasal verbs. As it can be seen, the mean of the control group is lower than the first test, but the means of the two experimental groups are higher than the first test. However, the overall mean of the three groups has fallen around .50. Whereas the control group has forgotten the meanings after this period, it is surprising that the two experimental groups have improved. However, the difference between the means of the three groups has increased from .60 in the Immediate Test to 3.53 in the Delayed Test. So, the difference is 6 times as much as the first test. The last point is that the ranking of the groups has radically changed. The highest mean belongs to the experimental Group II, and the lowest mean belongs to the Control Group. This is exactly opposite what happened in the first test.

TABLE 3:

DESCRIPTIVE STATISTICS OF DELAYED TEST OF TAUGHT PHRASAL VERBS

\begin{tabular}{|l|l|l|l|l|l|l|}
\hline Group & $\mathrm{N}$ & Mean & Std. Deviation & Minimum & Maximum & Std. Error Mean \\
\hline Control & 15 & 12.73 & 3.36 & 6 & 17 & 0.86 \\
\hline Experimental I & 15 & 15.86 & 2.06 & 11 & 18 & 0.53 \\
\hline Experimental II & 15 & 16.26 & 1.57 & 13 & 19 & 0.40 \\
\hline Total & 45 & 14.95 & 2.88 & 6 & 19 & \\
\hline
\end{tabular}

In order to compare the results of the three groups on the Delayed Test of Taught phrasal verbs, a one-way ANOVA was run. The F-observed value is 9.30 (Table 4). This amount of F-value is greater than the critical value of F at 2 and 42 degrees of freedom, i.e. 3.22. Since the observed F-value exceeded its critical value, it can be concluded that there are significant differences between the performances of the students taught through the techniques of Translation Equivalents, Sentential Contextualization, and Metaphorical Conceptualization. Thus, the students are not homogenous after receiving these types of instruction. In other words, the way of teaching phrasal verbs does affect the ability of the students in retaining the meaning of phrasal verbs after a long time. In other words, we can safely decide on the superiority of metaphorical conceptualization and sentential contextualization techniques in aiding the foreign language learners while learning the idiomatic phrasal verbs in the case of a delayed test. This can mean that mere memorization might equal the methods of sentential contextualization, and metaphorical conceptualization, but for a short time.

TABLE 4:

ONE-WAY ANOVA FOR THE DELAYED TEST OF TAUGHT PHRASAL VERBS

\begin{tabular}{|l|l|l|l|l|l|}
\hline & Sum of Squares & df & Mean Square & F & Sig. \\
\hline Between Groups & 112.311 & 2 & 56.156 & 9.300 & 0.000 \\
\hline Within Groups & 253.600 & 42 & 6.038 & & \\
\hline Total & 365.911 & 44 & & & \\
\hline
\end{tabular}


The post-hoc Scheffé test was run to compare the mean score of the control group with the two experimental groups (Sentential Contextualization and Metaphorical Conceptualization) on the delayed test of taught phrasal verbs. According to the results displayed in Table 5, the mean difference of $3.13(p<.05)$ indicates that there is a statistically significant difference between the Translation and Sentential Contextualization groups on the delayed test of taught phrasal verbs. Thus, the Sentential Contextualization group outperformed the Translation group on the delayed test of taught phrasal verbs. Furthermore, the mean difference of $3.53(p<.05)$ shows that there is a significant difference between Translation and Metaphorical Conceptualization groups on the delayed test of taught phrasal verbs. So, the Metaphorical Conceptualization group outperformed the Translation group. However, the mean difference between the two experimental groups of Sentential Contextualization and Metaphorical Conceptualization was not statistically significant. Therefore, the second null-hypothesis, stating that there is no significant difference between Experimental and Control Groups due to the effects of Translation, Sentential Contextualization and Metaphorical Conceptualization on the delayed test of taught phrasal verbs, was rejected.

TABLE 5:

POST-HOC SCHEFFE'S TEST FOR THE DELAYED TEST OF TAUGHT PHRASAL VERBS

\begin{tabular}{|c|c|c|c|c|c|c|}
\hline \multirow[b]{2}{*}{ (I) Groups } & \multirow[b]{2}{*}{ (J) Groups } & \multirow[b]{2}{*}{ Mean Difference(I-J) } & \multirow[b]{2}{*}{ Std. Error } & \multirow[b]{2}{*}{ Sig. } & \multicolumn{2}{|c|}{ 95\% Confidence Interval } \\
\hline & & & & & Lower Bound & Upper Bound \\
\hline \multirow[t]{2}{*}{ Control } & Experimental I & $-3.13333^{*}$ & .89726 & .005 & -5.4103 & -.8564 \\
\hline & Experimental II & $-3.53333^{*}$ & .89726 & .001 & -5.8103 & -1.2564 \\
\hline \multirow[t]{2}{*}{ Experimental I } & Control & $3.13333^{*}$ & .89726 & .005 & .8564 & 5.4103 \\
\hline & Experimental II & -.40000 & .89726 & .906 & -2.6770 & 1.8770 \\
\hline \multirow[t]{2}{*}{ Experimental II } & Control & $3.53333^{*}$ & .89726 & .001 & 1.2564 & 5.8103 \\
\hline & Experimental I & .40000 & .89726 & .906 & -1.8770 & 2.6770 \\
\hline
\end{tabular}

\section{Test of Untaught Phrasal Verbs}

For answering the third research question, a test consisting of 20 untaught phrasal verbs was administered 5 weeks after the instruction. This test, Test of Untaught phrasal verbs, was designed to measure the ability of the students to predict the meaning of untaught phrasal verbs which had the same particles, but were placed in a new sentence. Table 6 shows the descriptive statistics of the Test of Untaught phrasal verbs. The means of all the groups are lower than the first and second test, and this is not surprising since all the verbs are quite new to them. The overall mean of the three groups is 13.20, around 2.24 less than the first test. But the ranking of the groups according to the means is quite opposite the first test, and just like the delayed test. In other words, the experimental group II has the highest mean, followed by Sentential Contextualization and Translation groups respectively. The difference between the means of the three groups is 5.33. So, the mean difference is 9 times as much as the first test. Although the performances of the students seem to decline, it should be pointed out that the phrasal verbs are quite new to the students.

TABLE 6:

DESCRIPTIVE STATISTICS OF TEST OF UNTAUGHT PHRASAL VERBS

\begin{tabular}{|l|l|l|l|l|l|l|}
\hline Group & $\mathrm{N}$ & Mean & Std. Deviation & Minimum & Maximum & Std. Error Mean \\
\hline Control & 15 & 10.20 & 2.24 & 7 & 14 & .57 \\
\hline Experimental I & 15 & 13.86 & 1.50 & 11 & 16 & .38 \\
\hline Experimental II & 15 & 15.53 & 2.03 & 12 & 18 & .52 \\
\hline Total & 45 & 13.20 & 2.95 & 7 & 18 & \\
\hline
\end{tabular}

It is time to compare the results of the three groups on the Test of Untaught phrasal verbs, so a one-way ANOVA was employed in this stage. The F-observed value is 29.337 (Table 7). This amount of F-value is far greater than the critical value of $\mathrm{F}$ at 2 and 42 degrees of freedom, i.e. 3.22. Since the observed F-value is much more than its critical value, it can be concluded that there are significant differences between the performances of the students taught through the techniques of Translation, Sentential Contextualization, and Metaphorical Conceptualization in the prediction of the meaning of untaught phrasal verbs. In other words, different methods of teaching phrasal verbs influence the ability of the students in predicting the meaning of untaught phrasal verbs. Thus, we can safely reject the third null hypothesis stating that there is no significant difference between Experimental and Control Groups due to the effects of Translation, Sentential Contextualization and Metaphorical Conceptualization on the test of untaught phrasal verbs.

TABLE 7:

ONE-WAY ANOVA FOR THE TEST OF UNTAUGHT PHRASAL VERBS

\begin{tabular}{|l|l|l|l|l|l|}
\hline & Sum of Squares & df & Mean Square & F & Sig. \\
\hline Between Groups & 223.333 & 2 & 111.667 & 29.337 & .000 \\
\hline Within Groups & 159.867 & 42 & 3.806 & & \\
\hline Total & 383.200 & 44 & & & \\
\hline
\end{tabular}


A post-hoc Scheffé test was run to make a comparison between the mean scores of the control group with the two experimental groups (Sentential Contextualization and Metaphorical Conceptualization) on the test of untaught phrasal verbs. According to the results displayed in Table 8, the mean difference of $3.66(p<.05)$ indicates that a statistically significant difference was found between the Translation and Sentential Contextualization groups on this test of untaught phrasal verbs. Thus, the contextualization technique had been more helpful to the students in predicting the meaning of untaught phrasal verbs. Furthermore, the mean difference of $5.33(p<.05)$ shows that there is a significant difference between Translation and Metaphorical Conceptualization groups on the test of untaught phrasal verbs. So, the students who knew the metaphorical meaning of the particles could retain and predict the meaning of phrasal verbs better than those students taught through the Translation method. However, the mean difference between the two experimental groups of Sentential Contextualization and Metaphorical Conceptualization, 1.66, was not statistically significant. Therefore, the third null-hypothesis, stating that there is no significant difference between Experimental and Control Groups due to the effects of Translation, Sentential Contextualization and Metaphorical Conceptualization on the test of untaught phrasal verbs, was rejected.

This gives us strong evidence in favor of the view that metaphorical conceptualization plays a much more active role in the teaching/learning of idiomatic phrasal verbs when students come across the untaught idioms with the same particles as the taught ones. A brief look at the Tables brings us to the conclusion that in the short run it makes no difference which method of instruction is used. On the contrary, the sheer efficacy of metaphorical conceptualization when compared with the memorization technique is thoroughly clear in the long run.

TABLE 8:

POST-HOC SCHEFFE'S TEST FOR THE TEST OF UNTAUGHT PHRASAL VERBS

\begin{tabular}{|c|c|c|c|c|c|c|}
\hline \multirow[b]{2}{*}{ (I) Groups } & \multirow[b]{2}{*}{ (J) Groups } & \multirow[b]{2}{*}{ Mean Difference (I-J) } & \multirow[b]{2}{*}{ Std. Error } & \multirow[b]{2}{*}{ Sig. } & \multicolumn{2}{|c|}{$95 \%$ Confidence Interval } \\
\hline & & & & & Lower Bound & Upper Bound \\
\hline \multirow[t]{2}{*}{ Control } & Experimental I & $-3.66667^{*}$ & .71240 & .000 & -5.4745 & -1.8588 \\
\hline & Experimental II & $-5.33333^{*}$ & .71240 & .000 & -7.1412 & -3.5255 \\
\hline \multirow[t]{2}{*}{ Experimental I } & Control & $3.66667^{*}$ & .71240 & .000 & 1.8588 & 5.4745 \\
\hline & Experimental II & -1.66667 & .71240 & .076 & -3.4745 & .1412 \\
\hline \multirow[t]{2}{*}{ Experimental II } & Control & $5.33333^{*}$ & .71240 & .000 & 3.5255 & 7.1412 \\
\hline & Experimental I & 1.66667 & .71240 & .076 & -.1412 & 3.4745 \\
\hline
\end{tabular}

\section{CONCLUDing REMARKS}

The conclusion reached at considering the interpretation of results as regards the first hypothesis is that: if the teachers' focus of attention in teaching idiomatic phrasal verbs is on the immediate outcome of their instruction and the efficiency of teaching in a short and limited period of time is concentrated on, Translation technique is as efficient as Sentential Contextualization, and Metaphorical Conceptualization techniques. Prince (1996) and Qian (1996) obtained similar results from two experimental studies on the effect of different learning conditions on vocabulary acquisition. These studies suggested that presenting words in context does not have a more positive effect on learning vocabulary than the presentation of words in isolation along with their translation. Besides, the technique of metaphorical conceptualization is quite new to the students, and they have always been told to see the phrasal verbs as a whole, and learn them by heart. Students might not be accustomed to this method, and need more time than two hours to get the meaning of these particles. Furthermore, seeing and using phrasal verbs in sentences might seem an effective technique but as it will be discussed sentential context is not that effective and richer contexts are needed to guide the students guess the meaning of the phrasal verbs. In conclusion, these studies show that the use of context in learning vocabulary cannot guarantee it superiority in learning and acquisition in comparison to other modes of teaching. Nevertheless, since inferring from context is a common strategy in vocabulary and reading courses, it will be wise to investigate the effect of context in learning phrasal verbs in future to give us more support in accepting or rejecting these findings.

In contrast, if the effectiveness of teaching in the long run is the main objective of the instruction and the easier and delayed retention of idiomatic phrasal verbs is the ultimate aim pursued by teachers, orientational metaphors and contextualization techniques are much more effective and beneficial to the learners. This result corroborates the findings of Cooper (1999) and Hulstijn (1992). They obtained the conclusion that using context clues to guess the meaning of words is a good strategy in lexical acquisition. This is reflected in ESL/EFL vocabulary textbooks as well as being explored by some researchers. Cooper (1999) showed that successful learners use an inferring strategy to learn idioms. The findings of his study can be interpreted as follows: using context clues is possibly a successful strategy in the teaching and learning of multiword expressions. Hulstijn (1992)_found that the learners who inferred the meaning of target words remembered them better than the learners who were given the meaning of target words. This study showed that inferring helps learners retain the meaning of words, yet the technique of contextualization is not as effective as the metaphorical conceptualization. This might be due to the semantic idiomaticity of phrasal verbs. This means that 
semantic idiomaticity of phrasal verbs makes it difficult for learners to guess the meaning, so the use of context cannot be a good strategy to infer the idiomatic meanings. Thus, the inferring of incorrect meanings from context was sometimes a drawback, especially when there were no context clues. Furthermore, the present study used the sentential context for contextualized learning as well as for the contextualized production of phrasal verbs, which does not provide the readers with enough contexts. As Nation (2001) pointed out one or two sentences may not provide sufficient context from which learners infer the target word meaning.

The problem of unpredictability of the meaning of idioms can be tackled by looking at the particles that regularly appear in phrasal verbs, and indicating what each of them means by reference to the orientational metaphors embodied in each particle. If learners are made aware of metaphorical domains, they are capable of identifying metaphorical themes and of categorizing idioms independently. If so, when learners of English are made aware of the cognitive structures which underlie idioms, they would be able to grasp the figurative meaning of idioms more easily and they would retain these lexical items in their memory for a longer time. Collecting of idiomatic phrasal verbs relating to a particular conceptual domain by the teacher, writing them up on the board, and making the students supply the correct figurative meanings which come to their minds when they see a particular phrasal verb would also make learning more effective and enjoyable.

Teachers can use such techniques in their classes to teach phrasal verbs as matching a phrasal verb to its synonym, matching them to a picture, or even matching two halves of sentences. Miming, drawing, describing phrasal verbs or making sentences with them are also some of the popular activities suggested for teaching phrasal verbs. Students can be given sentences in which the phrasal verbs are missing, and the students should fill in the blanks in groups after discussing the meaning together. Writing paragraphs or even stories in which the new phrasal verbs are used can be a promising task, since it provides a more interesting activity and offers a richer context for learning and retaining the meaning of phrasal verbs. True-false exercises and puzzles are also suggested techniques for a better learning of phrasal verbs. Semantic mapping and semantic feature analysis techniques allow students to employ known structures in new contexts with new meanings and collocations. One semantic mapping technique is teaching phrasal verbs by "sorting them out" (analogies). This technique basically involves grouping phrasal verbs together according to the particle rather than the verb. All in all, learning phrasal verbs can be made a less challenging task by utilizing the above-mentioned techniques of semantic mapping and semantic feature analysis. Such techniques are quite impressive because they all provide varying but reasonable means for the disentanglement of the complex bundle of patterns of phrasal verbs. Hence, instead of telling students that they just have to learn phrasal verbs by heart, a teacher can choose and then apply the technique most suited to his or her classroom needs.

\section{APPENDIX A: IMMEdiate TeSt of TAUght Phrasal VerbS}

Instructions: Fill in the blanks with prepositions up, down, off, and out.

1. It is time to wind my speech I have a plane to catch.

2. It has been bucketing all day. We can't go out in the afternoon.

3. I was flattered to be offered the job but wasn't sure if I could carry it

4. We were off on Fridays. So, we didn't get until lunch time.

5. Management has been playing

6. I must remember to dig that book for you.

7. The official report plays ___ the likely benefits of the scheme.

8. We branched___ from the main road and turned down a country lane.

9. Let me jot____ your number and I'll call you tomorrow.

10. He blew ___ all the candles in the birthday party.

11. Tom peeled___ his wet t-shirt and hung them on the hook.

12. The rocket blasted___ at noon.

13. Fan the cards_, and then pick one.

14. Come on man, buck ___, things aren't that bad! It is not the end of the world.

15. Paul's legs were sticking ____ from under the car.

16. Would you hose ___ the car for me? It is so dirty.

17. What time does the laser show kick___ I am anxiously waiting for that.

18. I crossed__ 'Miss' and wrote 'Ms'.

19. The car broke___ just north of Paris, and we had to hire a taxi.

20. The taxi drew ___ outside the house, and we could see our parents coming.

\section{APPENDIX B: Delayed Test OF Untaught Phrasal Verbs}

1. Instructions: Fill in the blanks with prepositions up, down, off, and out.

2. Don't use all the milk, we need some for breakfast.

3. Please turn the volume ___ I I am trying to concentrate.

4. Every night we wipe the tables___ before we shut the restaurant. 
5. I will be home after midnight, so don't wait for me.

6 . We cuddled___ together and tried to get warm.

7. Where is everyone? They've all buggered

8. The factory next to our house is due to be pulled

9. Cut_the part of research which is about racial prejudice.

10. It is pelting ___ with rain. We can't go out now.

11. Don't worry, we'll figure something

12. I'll set___ early to avoid the traffic.

13. She tried to bolster my confidence ___ by saying that I had a special talent.

14. Click on a photo of any student, and it zooms___ to full size.

15. They managed to bring ___ the most daring jewelry robbery in history.

16. I am sure illnesses stand____ in all childhood memories.

17. Microsoft beat___ a rival company to win the contract.

18. She was ill, so I sent her some flowers to cheer her

19. Note the main points you want to include in your essay.

20. Joe was kicked the committee for stealing funds.

21. Police handcuffed him and hauled him to jail.

\section{APPENDIX C: THE PARTICLES AND THEIR ORIENTATIONAL METAPHORS}

\begin{tabular}{|l|l|l|}
\hline Particle & Meaning & Examples \\
\hline Up & Completion & Chew up, Use up, Give up \\
\hline Up & More & Turn up, Play up \\
\hline Up & Happy & Cheer up, Buck up, Feel up \\
\hline Up & Approach & Draw up, Bump up, Cuddle up \\
\hline Up & Out of bed & Wait up, Stay up, Get up \\
\hline Down & Raining & Beat down, Bucket down, Pelt down. \\
\hline Down & Less & Cool down, Play down, Turn down \\
\hline Down & Failure & Break down, Get down, Step down \\
\hline Down & Writing & Jot down, Note down, Pin down \\
\hline Down & Cleaning & Hose down, Scrub down, Wipe down \\
\hline Off & Departure & Back off, Blast off, Bog off, Hare off \\
\hline Off & Removal & Push off, Kick off, See off, Slip off \\
\hline Off & Separation & Block off, Box off, Cone off \\
\hline Off & Success & Come off, Carry off, Pass off, Pull off \\
\hline Off & Start & Get off, Kick off, Set off, Tee off. \\
\hline Out & Exclusion & Chuck out, Cross out, Cut out, Miss out \\
\hline Out & Solution & Big out, Drag out, Ferret out, Eke out \\
\hline Out & Appearance & Bring out, Pick out, Slip out, Stick out. \\
\hline Out & Extinction & Back out, Beat out, Blow out, Duck out \\
\hline Out & Extension & Carve out, Fluff out, Hew out, Fan out. \\
\hline
\end{tabular}

\section{REFERENCES}

[1] Bilkova, I. (2000). Czech and English idioms of body parts. M.P. dissertation. University of Glasgow.

[2] Black, J. C. (2002). Second language figurative proficiency: A comparative study of Malayan and English. Applied Linguistics, 23(1), 104-133.

[3] Cooper, T.C. (1999). Processing of idioms by L2 learners of English. TESOL Quarterly 33 (2), 233-262.

[4] Crutchley, A. (2007). Comprehension of idiomatic verb + particle constructions in 6- to 11-year-old children. First Language, 27 (3). 203-226. ISSN 0142-7237

[5] Gibbs, R.W. (1997). Metaphor in idiom comprehension. Journal of Memory and Language, 37, 141-154.

[6] Hulstijn, J. (1992). Retention of inferred and given word meanings: Experiments in incidental vocabulary learning. In P. Arnaud \& H. Bejoint (Eds.), Vocabulary and applied linguistics. London: MacMillan. 113-125.

[7] Ifill, T. (2002). Seeking the nature of idioms: A study in idiomatic structure. http://www.swarthmore.edu/SocSci/Linguistics/Papers/2003/ifill_tim.pdf. (Accessed 18/3/2005).

[8] Khatib, M. and Ghannadi, M. (2011). Interventionist (explicit and implicit) versus non-interventionist (incidental) learning of phrasal verbs by Iranian EFL learners. Journal of Language Teaching and Research, 2(3). 537-546.

[9] Kovecses, Z. \& Szabo, P. (1996). Idioms: A view from cognitive semantics. Applied Linguistics, 17(3), 326-355.

[10] Lakoff, G. (1987). Women, fire and dangerous things: What categories reveal about the mind. Chicago: University of Chicago Press.

[11] Nassaji, H. and Tian, J. (2010). Collaborative and individual output tasks and their effects on learning English phrasal verbs. Language Teaching Research, 14(4), 397-419.

[12] Nation, I. (2001). Learning vocabulary in another language. Cambridge: Cambridge University Press.

[13] Prince, $\mathrm{P}$ (1996). Second language vocabulary learning: The role of context versus translations as a function of proficiency. The Modern Language Journal, 80, 478-493. 
[14] Qian, D. (1996). ESL vocabulary acquisition: Contextualization and decontextualization. Canadian Modern Language Review, 53( 1), 120-42.

[15] Rundell, M. (2005a). Understanding phrasal verbs: Is there a system? MED Magazine, 30(5). http://macmillandictionaries.com/MED-Magazine/May2005/30-Corpora-Tips.htm. (Accessed 12/6/2007)

[16] Rundell, M. (2005b). Why are phrasal verbs so difficult? Humanizing Language Teaching, 7(3). http://www.hltmag.co.uk/may05/index.htm. (Accessed 23/9/2008)

[17] Side, R. (1990). Phrasal verbs: Sorting them out. ELT, 44(2), 144-159.

[18] Skoufaki, S. (2003). Verbal reports as a means to identify strategies of idiomatic meaning guessing. University of Cambridge Annual Report. http://www.iteslj.org. (Accessed 12/5/2006)

[19] Yasuda, S. (2010). Learning phrasal verbs through conceptual metaphors: A case of Japanese EFL learners. TESOL, 44(2), 250-273.

Mansoor Ganji is a lecturer of TEFL at the English Department of Chabahar Maritime University. He holds an M.A. in TEFL (Allameh Tabatabaii University, 2006), and a B.A. in Translation Studies (Chabahar Maritime University, 2002).

He started his career of teaching at Chabahar Maritime University and International University of Chabahar in 2006 and currently teaches graduate courses in Writing, Translation, Interpretation, and Methodology.

His main areas of interest include written feedback, collocation learning, and IELTS proficiency test. He has published some articles on TEFL in Journals of Applied Linguistics, and presented papers in national and international conferences. 